operation and a vision of a different future for mentally handicapped people whose lives are so often and so inappropriately in the hands of the medical profession.

REFERENCES

'DHSS (1971) Better Services for the Mentally Handicapped, Cmnd 4683
2 __ (1980) Mental Handicap: Progress, Problems and Priorities. $A$ review of mental handicap services in England since the 1971 White Paper.

3 ___ (1981) Care in Action: A handbook of Policies and Priorities for the Health and Personal Social Services in England.

4_ (1981) Care in the Community: A Consultative Document on Moving Resources for Care in England.

s___ (1983) Mental Handicap: Policies and Priorities.

\title{
Infant Psychiatry: Developments
}

\author{
D. Vorster, Consultant Child and Family Psychiatrist, Nuffield Clinic, Plymouth
}

Developments in preventive psychiatry should occur as a result of new knowledge of the psychiatry of infancy as presented at recent conferences: the International Conference of Child and Adolescent Psychiatry, Dublin 1982; the World Infant Psychiatry Congress at Cannes, March 1983; and the Child and Adolescent Psychiatry Congress in July 1983 at Lausanne.

Many papers describe the very early perceptual awareness of infants, their in-built cross modal abilities and the fine rhythmic relationship between mothers and their babies. In the US, 32,000 feet of film was run on 20 normal new-borns, indicating the intensity of work with infants these days.

At the Dublin Conference, findings concerning the 'attachment' and 'bonding' relationship with mother and augmentary caretakers were described by Levine on the psychobiological level revealing cortisone as the most sensitive indicator of a stressful situation and ameliorating support of the caretaker. Many papers described the state of confusion of babies when overwhelmed by stimuli, followed at a later age by withdrawal or attack. Sudden alteration in mother's facial expression can lead to these reactions-'a lack of response face'. The baby's heart rate responds in a discriminatory manner to touch by mother rather than stranger.

Crying is but one of the ways a baby may signal distress. Of 100 cases referred to our child psychiatry clinic (paper presented in Dublin), children with neuroses were described by mothers as 'crying babies', and those with behaviour disorders and psychosis as 'non-crying'. Mothers of crying babies failed to use the pacifier; mothers of non-crying babies also denied problems in themselves-indicating the interactional nature of the situation. Medical records in the main supported mothers' histories.

The import of early contact experienced by mothers and babies shortly after birth was stressed in a number of papers, and the therapeutic use of 'holding' described. Parental homework - the holding of autistic children-appeared to be of considerable value, according to a number of studies.

Following the work of Klaus, who described mother/baby contact for the first hour as leading to better interaction at age 5 years, de Chateau presented his recent work at the Cannes Conference indicating that by 3 years of age some of the positive effects in the index group above the control group had lessened, but there were biochemical changes and continuing favourable effects of the early contact. Since Klaus's work there have been many studies indicating the long-term favourable effects of early contact; others denying the permanence of these effects. Our recent study indicates that by age 6 weeks at developmental check-up, those mother/baby couples having had half an hour or more contact after birth had fewer problems than those with 5 minutes or less contact, or those having had a caesarian section or anaesthetic, etc, which necessitated mother/baby separation for half an hour or longer (Lausanne, July 1983). 'Holding' was found to be the commonest cry cure.

The great value of mother/baby units was described by French psychiatrists as serving 'a supportive grandparental function', and babies rarely needed removal from mothers with psychiatric disorder.

It is impossible in a short summary to discuss the very many interesting papers of well known authors, including Anthony, Hinde, Papousek, Brazeldon, Kennell, Bowlby and Stern.

Apart from early stress relief, infant psychiatry research is also of value in the treatment of already stressed individuals in childhood and possibly also in adult life, e.g. the value of holding autistic and hyperactive children. Knowledge of the minutely detailed interactive rhythms between babies and mothers in the earliest period should have repercussions concerning support services in maternity and paediatrics, and indicates the relevance of infant psychiatry to all age groups. 